\title{
THERMAL CONDUCTIVITY OF CARBON/BASAL FIBER REINFORCED EPOXY HYBRID COMPOSITES
}

\author{
I.D.G Ary Subagia ${ }^{1 *}$, I Ketut Gede Sugita ${ }^{1}$, I Ketut Gede Wirawan ${ }^{1}$, Ni Made Dwidiani ${ }^{1}$, \\ Akhmad Herman Yuwono ${ }^{2}$ \\ ${ }^{1}$ Department of Mechanical Engineering, Faculty of Engineering, Udayana University (UNUD), \\ Kampus Bukit Jimbaran, Badung, Bali 80362, Indonesia \\ ${ }^{2}$ Department of Metallurgy and Materials Engineering, Faculty of Engineering, Universitas Indonesia, \\ Kampus UI Depok, Depok 16424, Indonesia
}

(Received: February 2017 / Revised: June 2017 / Accepted: November 2017)

\begin{abstract}
The purpose of this paper is to analyse the thermal conductivity of carbon/basalt fiber reinforced hybrid composite structures based on stacking sequences. The paper also investigates the thermal impedance of carbon fiber reinforced polymer (CFRP) and basalt fiber reinforced polymer (BFRP) with increased thickness. Research involved processing hybrid composite by using injection moulding. The weight ratios of fibers to polymers was 60\%: 40\%. Testing was conducted using the ASTM D 5470 standard test method. Results show that the stacking sequences of carbon/basalt fibers have a significant impact on thermal conductivity. Hybrid composite with the stacking sequence mode $\mathrm{C}_{3} \mathrm{~B}_{4} \mathrm{C}_{3}$ has the lowest thermal conductivity at $0.187 \mathrm{~W} / \mathrm{mK}$, and the highest thermal impedance of $0.0052 \mathrm{~m}^{2} \mathrm{~K} / \mathrm{W}$. The highest thermal impedance of BFRP is at $0.007 \mathrm{~m}^{2} \mathrm{~K} / \mathrm{W}$ with $2.5 \mathrm{~mm}$ thickness. In CFRP, the highest thermal impedance is achieved by $3.4 \mathrm{~mm}$ thickness with $0.005 \mathrm{~m}^{2} \mathrm{~K} / \mathrm{W}$. Results therefore show that carbon/basalt/epoxy hybrid composites are good insulators, since thermal conductivity is less than $0.42 \mathrm{~W} / \mathrm{m}^{\circ} \mathrm{K}$ standard.
\end{abstract}

Keywords: Hybrid composite; Isolation; Stacking sequence; Thermal conductivity; Thermal impedance

\section{INTRODUCTION}

Over the last few decades, composites have been used widely in engineering products, owing to a wide range of beneficial properties, including low density, corrosion resistance, strength and durability, renewability, and low-cost production (Song et al., 2012). This study isolates several advantages of composites. Manufacturing of composites is currently carried out by combining two or more different fibers, reinforcing as a single matrix to maximise beneficial properties (Mingchao et al., 2009; Dehkordi et al., 2010). This material is subsequently known as a hybrid composite (Ashby \& Brechet, 2003). Hybrid composites can significantly improve mechanical properties, including ultimate strain and impact (Pandya et al., 2011). Badie et al. (2011) study drive shafts made of a hybrid composite, basing their study on the angle of fiber orientation and stacking sequences. They examine the drive shaft's tensile stiffness, natural frequency, stress buckling, fatigue life, and failure mode. Zhang et al. (2012) study the lightweight bearing load of glass/carbon fibers reinforced hybrid composite laminate. Flexural properties of hybrid composite with reinforced glass/carbon fibers have been subsequently studied by Dong et al.

\footnotetext{
*Corresponding author's email: arsubmt@me.unud.ac.id, Tel: +62-81353651467, Fax.+62-361-703321 Permalink/DOI: https://doi.org/10.14716/ijtech.v8i8.701
} 
(2012). Tensile strength and flexural strength of inter-ply carbon/basalt fibers reinforced hybrid composite has been studied by Subagia and Kim (2013) and Subagia and Kim (2014a), respectively. Subagia et al. (2014c) also study hybrid basalt fiber and tourmaline micro/nano particles. Such research shows that basalt fibers influence the flexural strength of composites up to $70 \%$ (Nurjaya et al., 2015). Additionally, the effect of stacking sequences on mechanical properties has been studied by Onal and Adanur, (2002), Mariatti et al. (2003), Agarwal et al. (2014), Lim et al. (2014), and Subagia et al. (2014b).

Thermal conductivity comprises the physical properties of materials that indicate the rate at which heat flows through a given material. Several studies have been carried out in the last decades with the aim of improving the thermal conductivity of composites. For example, Yamashita et al. (2008), investigate the thermal conductivity of plain weave fabrics and plain weave fabric/resin composites. Their study confirms that the anisotropic behaviour of the composite influences thermal conductivity. Research into the effects of filler size distribution on thermal conductivity of composites was conducted by Holotescu and Stoian (2009). An investigation of thermal conductivity with imperfect interfaces on composite materials was carried out by Marcos-Gomez et al. (2010). The thermal conductivity of composite material using wastes wood and expanded polystyrene was studied by Agoua et al. (2013). The effect of carbon nano-tubes (CNT) and carbon fiber reinforced composites on thermal conductivity was studied by Park et al. (2014). Agrawal and Satapathy, (2015) determined the thermal conductivity of polymer composites with hybrid filler using a mathematic model. The effect of stacking sequences on the effective thermal conductivity of unidirectional composite laminates has been studied by $\mathrm{Yu}$ et al. (2015). Despite all this research, until now there have not been many studies of the effect of stacking sequences on the thermal conductivity of composite hybrid laminate.

The main aim of the experiment detailed in this paper is to determine the thermal conductivity and thermal impedance of hybrid composites based on their stacking sequences. The study also investigates the influence of thickness on the thermal impedance of CFRP and BFRP.

\section{EXPERIMENTAL}

\subsection{Materials}

Carbon fibers and basalt fibers are used as reinforcement materials. Woven mat strands composed of carbon fiber (C120-3K) are produced by Hyundai Fiber Co Ltd (Korea). C120-3K has a density of $114 \mathrm{lb} / \mathrm{ft}^{3}\left(1800 \mathrm{~kg} / \mathrm{m}^{3}\right)$ and an elastic modulus of $240 \mathrm{GPa}$. Woven mat strands composed of basalt fiber (EcoB4-F210) are manufactured by Seco-Tech (Korea) (Subagia et al., 2014b). EcoB4-F210 has density of $2.7 \mathrm{~g} / \mathrm{cm}^{3}$ and an elastic modulus of $89 \mathrm{GPa}$. Basalt fiber is made from volcanic magma; rock is melted at $1300-1700^{\circ} \mathrm{C}$ and spun (Singha, 2012). Besides having good mechanical properties, basalt also has a high thermal stability, good electrical and sound insulating properties, and it a high chemical resistance. Basalt fiber is a new material for composite reinforcement that can replace glass fiber. The matrix is composed of epoxy resin (Modified BPA Epoxy Resin) produced by Jet Korea Industrial Corporation. The hardener used comprises modified Aliphatic Amine (Subagia \& Kim, 2013). The epoxy resin is used owing to its low cost, good electrical and mechanical properties, and ease of handling (Murthy et al., 2012). The epoxy has a density and elastic modulus of $1350 \mathrm{~kg} / \mathrm{m}^{3}$ and $3.25 \mathrm{GPa}$, respectively. 


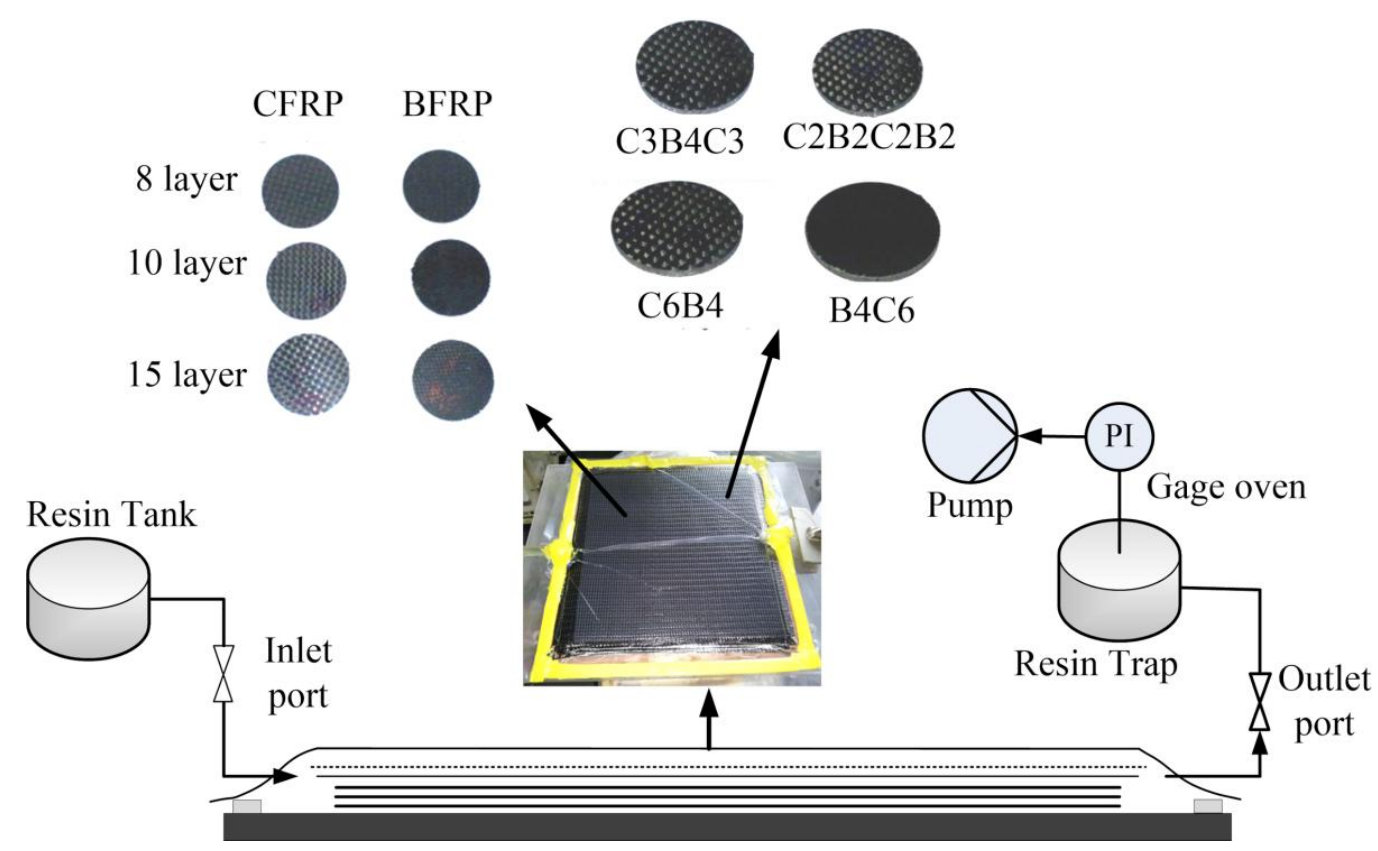

Figure 1 Injection procedure for hybrid composite manufacture

\subsection{Manufacturing Procedure}

Hybrid composite is fabricated using an injection molding procedure. The injection molding process is illustrated in Figure 1. It consist of five steps: fiber lamination and mold preparation, matrix preparation, injection process, curing, and specimen preparation. The sequence order is designed as $\left[\mathrm{C}_{6} / \mathrm{B}_{4}\right] ;\left[\mathrm{B}_{4} / \mathrm{C}_{6}\right] ;\left[\mathrm{C}_{3} / \mathrm{B}_{4} / \mathrm{C}_{3}\right]$; and $\left[\mathrm{C}_{2} / \mathrm{B}_{2} / \mathrm{C}_{2} / \mathrm{B}_{2} / \mathrm{C}_{2}\right]$ as shown in Table 1 and Table 2. Capital letters $[\mathrm{C}]$ and $[\mathrm{B}]$ function as abbreviations of carbon fiber and basalt fibers, respectively. Suffix numbers are employed as code for the number of layers. The fiber orientation is 90/90 with 10 layers in total. Carbon fiber reinforced plastics (CFRP) and Basalt fiber reinforced plastics (BFRP) have been manufactured as controls. The difference in thickness between CFRP and BFRP was created using 8, 10 and 15 layers. For the test, each thickness was cut to a test specimen of $30 \mathrm{~mm}$ diameters.

Table 1 Thermal conductivity of hybrid composite

\begin{tabular}{lcccc}
\hline Composite Items & Code & $\begin{array}{c}\text { Thickness } \\
(\mathrm{m})\end{array}$ & $\begin{array}{c}\text { Thermal Impedance } \\
{\left[\mathrm{m}^{2} \mathrm{~K} / \mathrm{W}\right]}\end{array}$ & $\begin{array}{c}\text { Thermal Conductivity } \\
{[\mathrm{W} / \mathrm{mK}]}\end{array}$ \\
\hline CFRP & $\mathrm{CF}-2$ & 0.025 & 0.0043 & 0.276 \\
BFRP & $\mathrm{BF}-2$ & 0.019 & 0.0052 & 0.018 \\
{$\left[\mathrm{C}_{3} \mathrm{~B}_{4} \mathrm{C}_{3}\right]_{10}$} & $\mathrm{H}_{1}$ & 0.021 & 0.0052 & 0.187 \\
{$\left[\mathrm{C}_{2} \mathrm{~B}_{2} \mathrm{C}_{2} \mathrm{~B}_{2} \mathrm{C}_{2}\right]_{10}$} & $\mathrm{H}_{2}$ & 0.020 & 0.0047 & 0.206 \\
{$\left[\mathrm{C}_{6} \mathrm{~B}_{4}\right]_{10}$} & $\mathrm{H}_{3}$ & 0.021 & 0.0045 & 0.211 \\
{$\left[\mathrm{~B}_{4} \mathrm{C}_{6}\right]_{10}$} & $\mathrm{H}_{4}$ & 0.020 & 0.0046 & 0.212 \\
\hline
\end{tabular}

Table 2 Thermal conductivity of CFRP and BFRP

\begin{tabular}{lccc}
\hline \multicolumn{1}{c}{ Composite Items } & Code & $\begin{array}{c}\text { Thickness } \\
{[\mathrm{m}]}\end{array}$ & $\begin{array}{c}\text { Thermal Impedance } \\
{\left[\mathrm{m}^{2} \mathrm{~K} / \mathrm{W}\right]}\end{array}$ \\
\hline$[\mathrm{CFRP}]_{8}$ & $\mathrm{CF}-1$ & 0.017 & 0.004 \\
{$[\mathrm{CFRP}]_{10}$} & $\mathrm{CF}-2$ & 0.020 & 0.004 \\
{$[\mathrm{CFRP}]_{15}$} & $\mathrm{CF}-3$ & 0.034 & 0.005 \\
{$[\mathrm{BFRP}]_{8}$} & $\mathrm{BF}-1$ & 0.018 & 0.005 \\
{$[\mathrm{BFRP}]_{10}$} & $\mathrm{BF}-2$ & 0.020 & 0.005 \\
{$[\mathrm{BFRP}]_{15}$} & $\mathrm{BF}-3$ & 0.025 & 0.007 \\
\hline
\end{tabular}




\subsection{Data Analysis}

The thermal conductivity of hybrid composites has been tested using the Guarded Heater Test Stack, based on the ASTM D5470 standard method. The schematic test is shown in Figure 2a. Three specimens of each variation of thickness and stacking sequence were tested at a temperature of $60 \pm 2^{\circ} \mathrm{C}$ and at $20 \mathrm{~kg}$ applied loads. The specimens were tested using a consistent method for 60 minutes.
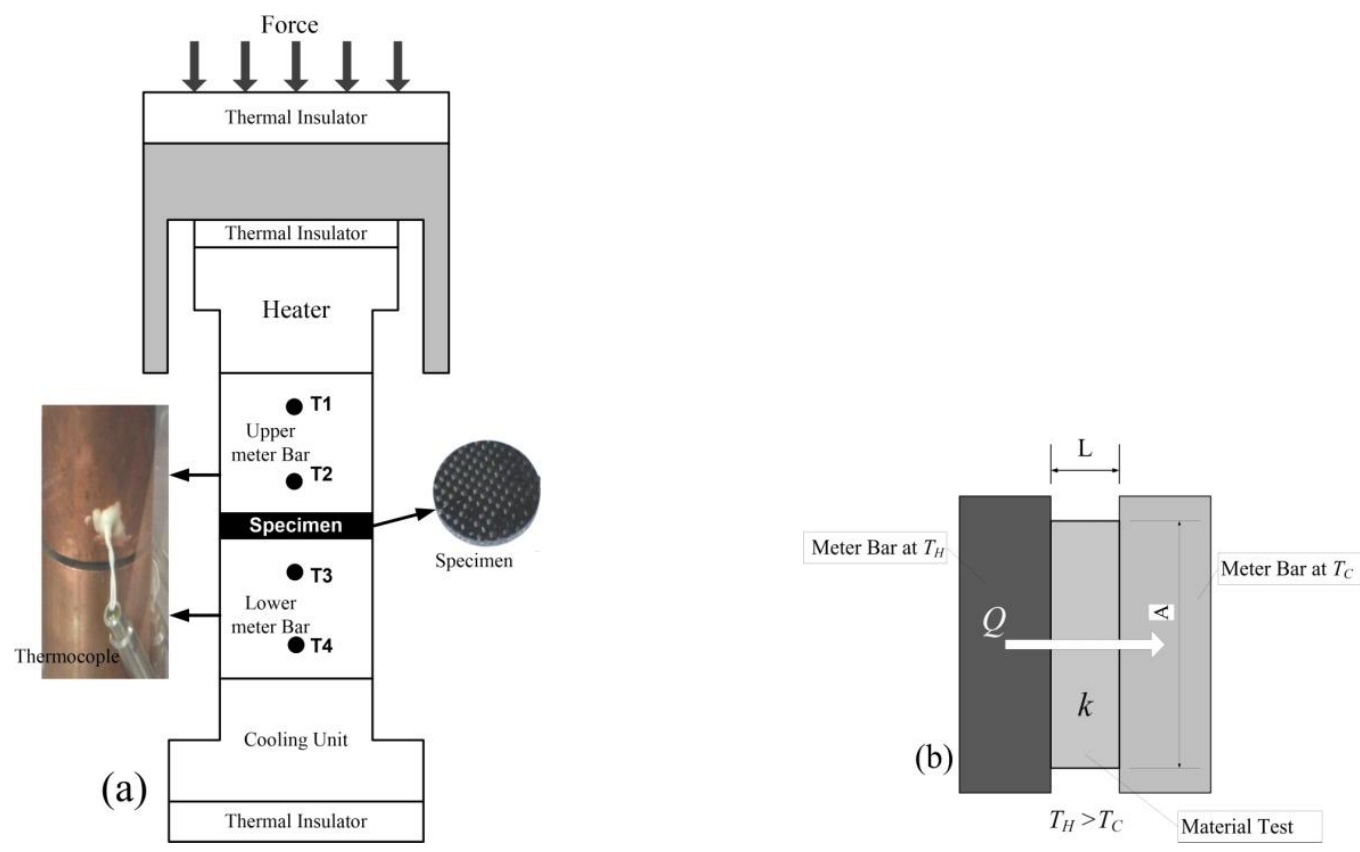

Figure 2 Schematic Test of Thermal Conductivity Set-Up by ASTM D5470 Standard

As illustrated in Figure 2b, there are two meter bars: a hot meter bar and a cold meter bar. The temperature of the hot meter bar surfaces that are in contact with the specimen can be calculated using the following equation;

$$
T_{H}=T_{2}-\frac{d_{B}}{d_{A}}\left[T_{1}-T_{2}\right]
$$

The side temperature of the specimen in contact with the surface of the cold meter bar can be calculated using the following equation;

$$
T_{C}=T_{3}-\frac{d_{D}}{d_{C}}\left[T_{3}-T_{4}\right]
$$

where $T_{H}$ and $T_{C}$ constitute the temperature of the hot meter bar and cold meter bar surfaces in contact with the specimen $[\mathrm{K}]$, respectively, $T_{1}$ and $T_{2}$ are the warmer and cooler temperatures of the hot meter bar $[\mathrm{K}], \mathrm{T}_{3}$ and $\mathrm{T}_{4}$ are the warmer and cooler temperatures on the cold meter bar $[\mathrm{K}], d_{\mathrm{A}}$ is the distance between $T_{1}$ and $T_{2}[\mathrm{~m}], d_{\mathrm{B}}$ is the distance between the surface of the hot meter bar in contact with specimen to the $T_{2}(\mathrm{~m}), d_{\mathrm{C}}$ is distance between $T_{3}$ and $T_{4}(\mathrm{~m}), d_{\mathrm{D}}$ is the distance between the surface of the hot meter bar in contact with the specimen to the $T_{3}(\mathrm{~m})$.

$$
\theta=\frac{A}{Q}\left[T_{H}-T_{C}\right]\left(\mathrm{K} \cdot \mathrm{m}^{2}\right) / \mathrm{W}
$$


The thermal conductivity of the composite material according to proportional constants can be determined using the equation;

$$
\begin{gathered}
Q=\frac{K A(\Delta T)}{L} \\
K=\frac{L}{R} ; R=\frac{\left(T_{H}-T_{C}\right)}{Q / A}
\end{gathered}
$$

where $Q$ is the heat flow rate of the isothermal surface [W], the area of the material test surface is $A\left[\mathrm{~m}^{2}\right]$, and the specimen thickness or the gap of the meter bar is denoted as $L(\mathrm{~m})$, with $\mathrm{R}$ constituting the thermal resistance in surfaces.

\section{RESULTS AND DISCUSSION}

Theoretically, it is known that the properties of the composite materials are extremely dependent on the constituents used in the strengthening of the fiber and matrix. In order to improve the characteristics and the performance of FRP composites, hybridization is generally seen as a good solution. Yu et al. (2015) have looked into stacking sequences as one structural approach that can influence effective thermal conductivity (Yu et al., 2015). The thermal conductivity of carbon/basalt fiber hybrid composites with difference stacking sequences and specimen controls (CFRP and BFRP) are presented in Table 1. The results indicate that CFRP has the highest thermal conductivity at $0.276[\mathrm{~W} / \mathrm{mK}], 93 \%$ of BFRP at $0.018[\mathrm{~W} / \mathrm{mK}]$. However, the thermal impedance of BFRP is highest with $0.0052\left[\mathrm{~m}^{2} \mathrm{~K} / \mathrm{W}\right]$. CFRP has the lowest thermal impedance at $0.0043\left[\mathrm{~m}^{2} \mathrm{~K} / \mathrm{W}\right]$. The thermal conductivity of hybrid composites is 0.187 to $0.212[\mathrm{~W} / \mathrm{mK}]$ depending on the stacking sequence. Thus hybridization is an effective way to modify thermal conductivity. Table 2 shows the thermal impedance of CFRP and BFRP, according to different numbers of layers and thicknesses. In both CFRP and BFRP, thermal impedance increases with higher numbers of layers. CFRP with 8 layers at $0.017 \mathrm{~m}$ thickness has the lowest thermal impedance: $0.004 \mathrm{~m}^{2} \mathrm{~K} / \mathrm{W}$. CFRP with 15 layers at $0.02 \mathrm{~m}$ thickness has the highest thermal impedance: $0.005 \mathrm{~m}^{2} \mathrm{~K} / \mathrm{W}$. BFRP with 8 layers at $0.018 \mathrm{~m}$ thickness has a thermal impedance of $0.005 \mathrm{~m}^{2} \mathrm{~K} / \mathrm{W}$. BFRP with 15 layers at $0.025 \mathrm{~m}$ thickness has a thermal impedance of $0.007 \mathrm{~m}^{2} \mathrm{~K} / \mathrm{W}$. It can be subsequently concluded that higher thickness produces higher thermal impedance. This can be effectively employed as a solution for thermal insulation and electrical devices.

Figure 3 shows the thermal impedance of hybrid composites with different carbon/basalt fibers stacking sequences for 10 layers in total. It shows that the thermal impedance of $\mathrm{H} 1, \mathrm{H} 2, \mathrm{H} 3$ and $\mathrm{H} 4$ decrease linearly from the thermal impedance of $\mathrm{B}_{10}$ (BFRP). The latter nonetheless has a higher thermal impedance than $\mathrm{C}_{10}$ (CFRP). It can be concluded that basalt fiber volumetric stability is maintained at a high temperature owing to basalt fibers nucleation at high temperatures (Borhan, 2013; Gori \& Corasaniti, 2014). In these results, H1, with laminate orientation $\mathrm{C}_{3} \mathrm{~B}_{4} \mathrm{C}_{3}$, has a highest thermal impedance value compared with other stacking sequences models. At the same time, $\mathrm{H} 2, \mathrm{H} 3$ and $\mathrm{H} 4$ have similar thermal impedance values and an average difference in thermal impedance of stacking sequence hybrid composites compared to $\mathrm{B}_{10}$ of $9.7 \%$. This shows that the stacking sequence is not a significant influence on thermal impedance. 


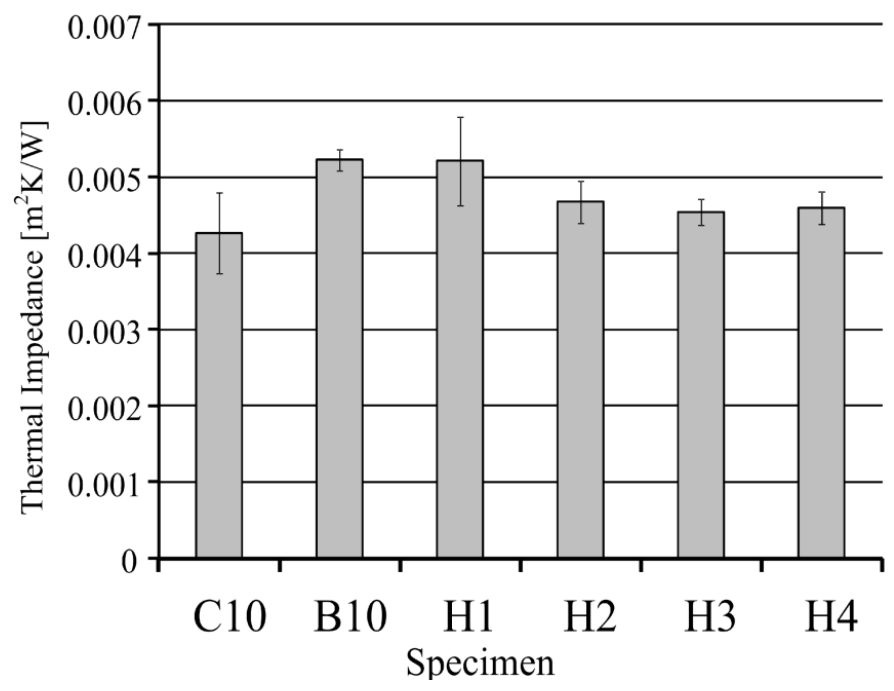

Figure 3 Thermal impedance hybrid composite of 10 layers

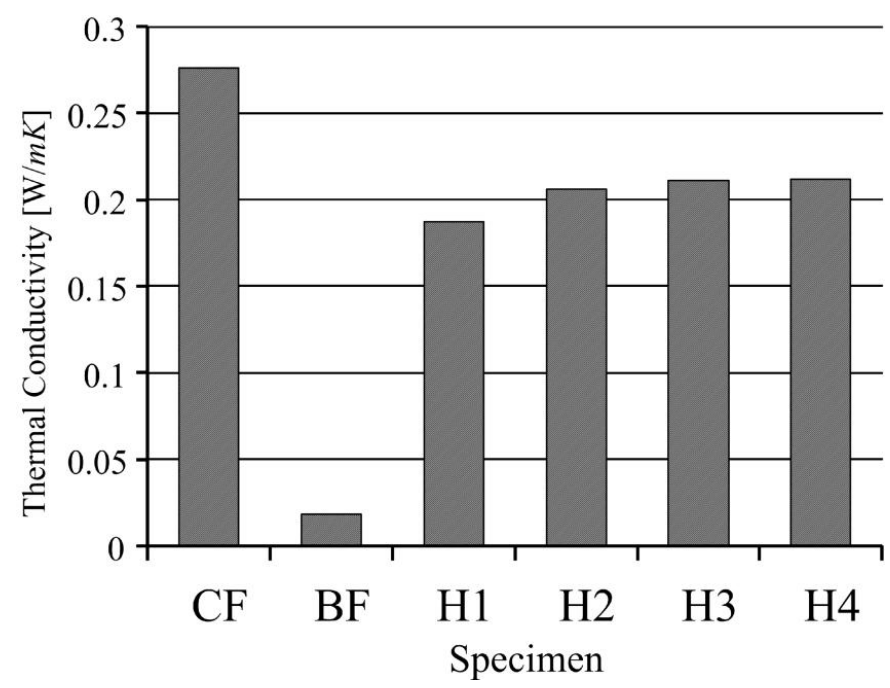

Figure 4 Thermal conductivity hybrid composite on 10 layers

Figure 4 shows the thermal conductivity of hybrid composites. Ten layers of reinforcement fibers (carbon fiber and basalt fiber) were stacked, based on the stacking sequence mode in the epoxy matrix. As is shown in Figure 4, thermal conductivity CFRP has a higher value than BFRP. Hybrid composites have a level of thermal conductivity between CFRP and BFRP. The comparison of thermal impedance as related to thickness of CFRP and BFRP is shown in Figure 5. Three of the thicknesses according to the number of layers CFRP and BFRP were tested: 8, 10 and 15 layers. Generally, for the same amount of fiber layers, BFRP exhibits a higher average thermal impedance of $20 \%$ compared with CFRP. However, BFRP with 8 layers at $0.018 \mathrm{~m}$ thickness has a thermal impedance of $0.005 \mathrm{~m}^{2} \mathrm{~K} / \mathrm{W}$, which is equal to CFRP with 15 layers at $0.034 \mathrm{~m}$ thickness. This suggests that basalt fiber has a higher temperature stability than carbon fiber. Result thus shows that basalt fiber is an excellent insulating material.

Figures $6 \mathrm{a}$ to $6 \mathrm{c}$ illustrate the internal condition of hybrid composites after the test. The internal condition of specimens are ascertained using a Scanning Electron Microscope (SEM) JEOL JSM 5900) at $10 \mathrm{kV}$ with magnification of $20 \mu \mathrm{m}, 100 \mu \mathrm{m}$, and $500 \mu \mathrm{m}$. As can be seen in Figure 6a, laminate basalt fibers in carbon fiber were carried out as stacking sequences. 


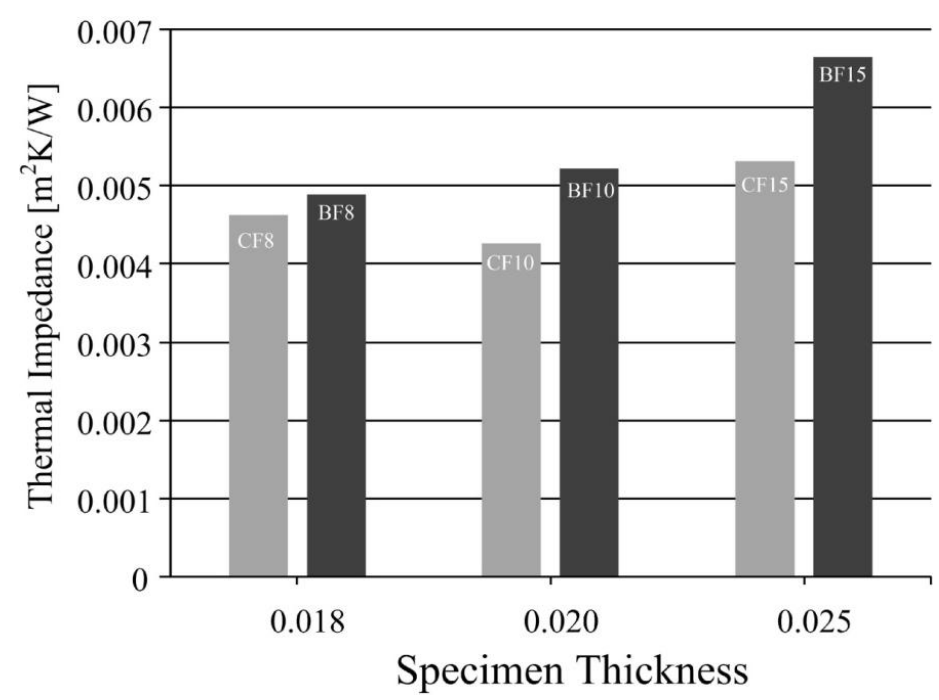

Figure 5 Thermal impedance of CFRP and BFRP based on composite thickness

Following heat transfer, no structural changes of the laminate between the carbon fiber and basalt fibers is detected, as the temperature of the test is lower than the melting temperatures of fibers. Temperatures are not high enough to alter material phases. Generally, damage occurs as a result of mechanical behaviors. Figure $6 \mathrm{~b}$ shows the internal surfaces of BFRP after a heat transfer of $60^{\circ} \mathrm{C}$ for as long as 60 minutes. Figure $6 \mathrm{c}$ shows the internal surfaces for CFRP during a similar process.
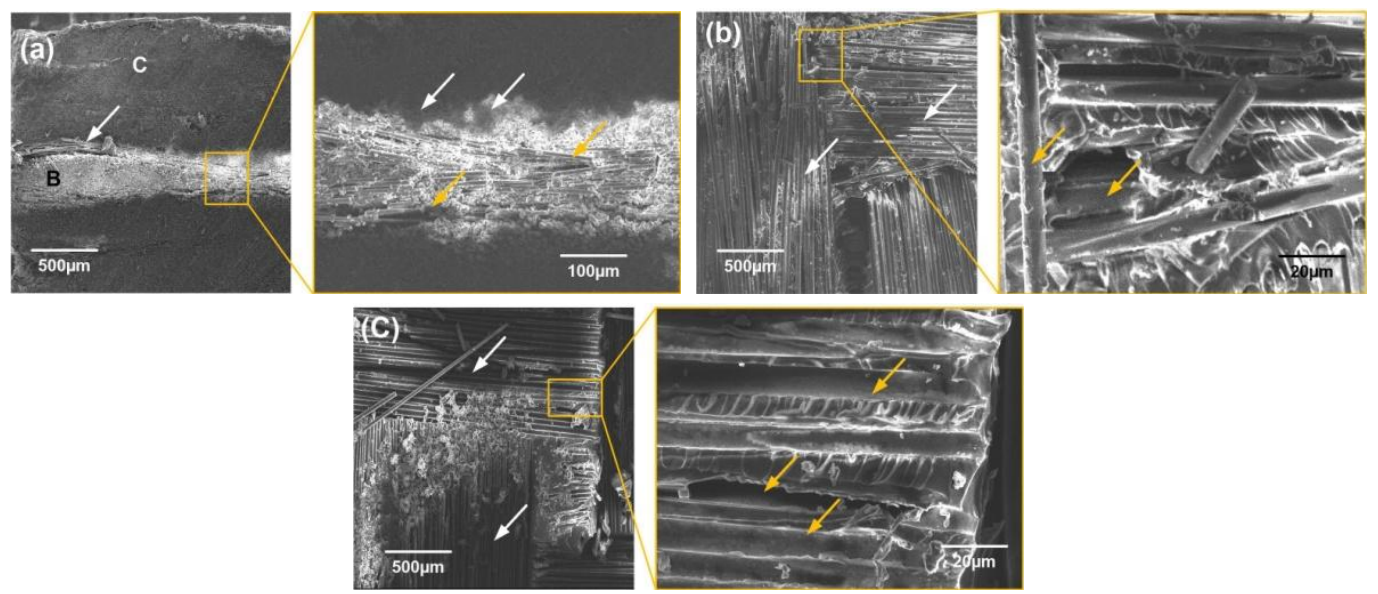

Figure 6 Internal condition of hybrid composites: (a) Carbon/basalt/epoxy hybrid composite laminate;

(b) Internal surface of BFRP; and (c) Internal surfaces off CFRP

\section{CONCLUSION}

The results show that the stacking sequences of carbon/basalt fibers have a significant impact on thermal conductivity. Hybrid composites with the stacking sequence mode C3B4C3 exhibit the lowest thermal conductivity at $0.187 \mathrm{~W} / \mathrm{mK}$, and the highest thermal impedance at 0.0052 $\mathrm{m}^{2} \mathrm{~K} / \mathrm{W}$. The highest thermal impedance in BFRP is $0.007 \mathrm{~m}^{2} \mathrm{~K} / \mathrm{W}$ with $2.5 \mathrm{~mm}$ thicknesses. In CFRP, the highest thermal impedance is achieved by $3.4 \mathrm{~mm}$ thicknesses with $0.005 \mathrm{~m}^{2} \mathrm{~K} / \mathrm{W}$. It is subsequently shown that carbon/basalt/epoxy hybrid composites operate as good insulators, because the thermal conductivity is smaller than the $0.42 \mathrm{~W} / \mathrm{m}^{\circ} \mathrm{K}$ standard. It can be concluded that stacking sequences in carbon/basalt/epoxy hybrid composite laminates is an effective way to modify the thermal conductivity of composite materials in engineering products. Moreover, 
basalt fiber has a higher temperature stability than carbon fiber. Basalt fiber is therefore an excellent insulating material. Furthemore, it can be concluded that temperature is an effective influence on material structure. However, material structures cannot change when temperatures are lower than melting temperatures.

\section{ACKNOWLEDGEMENT}

The author grateful to the Republic of Indonesia, Ministry of Research, Technology and Higher Education for funding this research project (contract number: 415.56/UN14.4.A/PL/2017). The author would also like to extend thanks to USAID and the EPI-UNET program who have supported the realization of this paper.

\section{REFERENCES}

Agarwal, G., Patnaik, A., Kumar Sharma, R., Agarwal, J., 2014. Effect of Stacking Sequence on Physical, Mechanical and Tribological Properties of Glass-carbon Hybrid Composites. Friction, Volume 2(4), pp. 354-364

Agoua, E., Allognon-Houessou, E., Adjovi, E., Togbedji, B., 2013. Thermal Conductivity of Composites Made of Wastes of Wood and Expanded Polystyrene. Construction and Building Materials, Volume 41, pp. 557-562

Agrawal, A., Satapathy, A., 2015. Mathematical Model for Evaluating Effective Thermal Conductivity of Polymer Composites with Hybrid Fillers. International Journal of Thermal Sciences, Volume 89, pp. 203-209

Ashby, M., Brechet, Y., 2003. Designing Hybrid Materials. Acta Materialia, Volume 51(19), pp. 5801-5821

Badie, M., Mahdi, E., Hamouda, A., 2011. An Investigation into Hybrid Carbon/Glass Fiber Reinforced Epoxy Composite Automotive Drive Shaft. Materials \& Design, Volume 32(3), pp. $1485-1500$

Borhan, T.M., 2013. Thermal and Mechanical Properties of Basalt Fibre Reinforced Concrete. World Academy of Science, Engineering and Technology, International Journal of Civil and Environmental Engineering, Volume 7(4), pp. 334-337

Dehkordi, M.T., Nosraty, H., Shokrieh, M.M., Minak, G., Ghelli, D., 2010. Low Velocity Impact Properties of Intra-ply Hybrid Composites based on Basalt and Nylon Woven Fabrics. Materials \& Design, Volume 31(8), pp. 3835-3844

Dong, C., Ranaweera-Jayawardena, H.A., Davies, I.J., 2012. Flexural Properties of Hybrid Composites Reinforced by S-2 Glass and T700s Carbon Fibres. Composites Part B: Engineering, Volume 43(2), pp. 573-581

Gori, F., Corasaniti, S., 2014. Effective Thermal Conductivity of Composites. International Journal of Heat and Mass Transfer, Volume 77, pp. 653-661

Holotescu, S., Stoian, F.D., 2009. Evaluation of the Effective Thermal Conductivity of Composite Polymers by Considering the Filler Size Distribution Law. Journal of Zhejiang University-SCIENCE A, Volume 10(5), pp. 704-709

Lim, J.I., Rhee, K.Y., Kim, H.J., Jung, D.H., 2014. Effect of Stacking Sequence on the Flexural and Fracture Properties of Carbon/Basalt/Epoxy Hybrid Composites. Carbon Letters, Volume 15(2), pp. 125-128

Marcos-Gomez, D., Ching-Lloyd, J., Elizalde, M., Clegg, W., Molina-Aldareguia, J., 2010. Predicting the Thermal Conductivity of Composite Materials with Imperfect Interfaces. Composites Science and Technology, Volume 70(16), pp. 2276-2283

Mariatti, M., Nasir, M., Ismail, H., 2003. Effect of Stacking Sequence on the Properties of Plain-Satin Hybrid Laminate Composites. Polymer-Plastics Technology and Engineering, Volume 42(1), pp. 65-79 
Mingchao, W., Zuoguang, Z., Zhijie, S., 2009. The Hybrid Model and Mechanical Properties of Hybrid Composites Reinforced with Different Diameter Fibers. Journal of Reinforced Plastics and Composites, Volume 28(3), pp. 257-264

Murthy, B., Rodrigues, L., Devineni, A., 2012. Process Parameters Optimization in Gfrp Drilling through Integration of Taguchi and Response Surface Methodology. Research Journal of Recent Sciences, Volume 1(6), pp. 7-15

Nurjaya, D.M., Astutiningsih, S., Zulfia, A., 2015. Thermal Effect on Flexural Strength of Geopolymer Matrix Composite with Alumina and Wollastonite as Fillers. International Journal of Technology, Volume 6(3), pp. 462-470

Onal, L., Adanur, S., 2002. Effect of Stacking Sequence on the Mechanical Properties of Glasscarbon Hybrid Composites Before and After Impact. Journal of Industrial Textiles, Volume 31(4), pp. 255-271

Pandya, K.S., Veerraju, C., Naik, N., 2011. Hybrid Composites Made of Carbon and Glass Woven Fabrics under Quasi-static Loading. Materials \& Design, Volume 32(7), pp. 4094 4099

Park, J.-M., Kwon, D.-J., Wang, Z.-J., Roh, J.-U., Lee, W.-I., Park, J.-K., DeVries, K.L., 2014. Effects of Carbon Nanotubes and Carbon Fiber Reinforcements on Thermal Conductivity and Ablation Properties of Carbon/Phenolic Composites. Composites Part B: Engineering, Volume 67, pp. 22-29

Singha, K., 2012. A Short Review on Basalt Fiber. International Journal of Textile Science, Volume 1(4), pp. 19-28

Song, M., Sankar, B., Subhash, G., Yen, C., 2012. Analysis of Mode I Delamination of ZPinned Composites using a Non-dimensional Analytical Model. Composites Part B: Engineering, Volume 43(4), pp. 1776-1784

Subagia, I.D.G., Kim, Y., 2014a. Tensile Behavior of Hybrid Epoxy Composite Laminate Containing Carbon and Basalt Fibers. Science and Engineering of Composite Materials, Volume 21(2), pp. 211-217

Subagia, I.D.G.A., Kim, Y., 2013. A Study on Flexural Properties of Carbon-basalt/Epoxy Hybrid Composites. Journal of Mechanical Science and Technology, Volume 27(4), pp. 987

Subagia, I.D.G.A., Kim, Y., Tijing, L.D., Kim, C.S., Shon, H.K., 2014b. Effect of Stacking Sequence on the Flexural Properties of Hybrid Composites Reinforced with Carbon and Basalt Fibers. Composites Part B: Engineering, Volume 58, pp. 251-258

Subagia, I.D.G.A., Tijing, L.D., Kim, Y., Kim, C.S., Vista IV, F.P., Shon, H.K., 2014c. Mechanical Performance of Multiscale Basalt Fiber-epoxy Laminates Containing Tourmaline Micro/Nano Particles. Composites Part B: Engineering, Volume 58, pp. 611617

Yamashita, Y., Yamada, H., Miyake, H., 2008. Effective Thermal Conductivity of Plain Weave Fabric and Its Composite Material Made from High Strength Fibers. Journal of Textile Engineering, Volume 54(4), pp. 111-119

$\mathrm{Yu}$, H., Heider, D., Advani, S., 2015. Role of in-Plane Stacking Sequence on Transverse Effective Thermal Conductivity of Unidirectional Composite Laminates. International Journal of Heat and Mass Transfer, Volume 85, pp. 897-903

Zhang, J., Chaisombat, K., He, S., Wang, C.H., 2012. Hybrid Composite Laminates Reinforced with Glass/Carbon Woven Fabrics for Lightweight Load Bearing Structures. Materials \& Design, Volume 36, pp. 75-80 